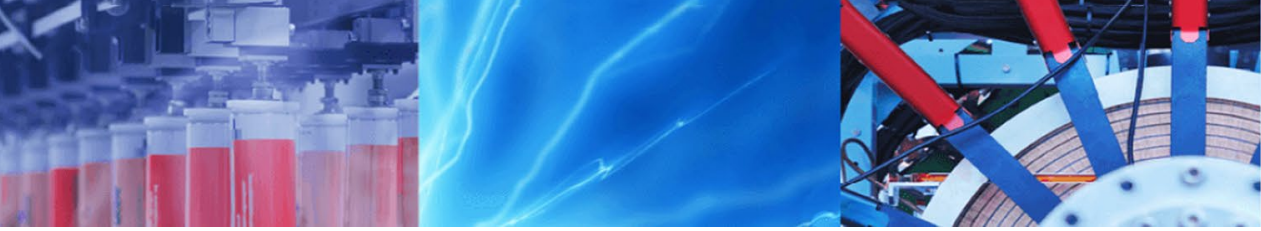

Research Article

\title{
Assessment of the colloidal montmorillonite dispersion as a low-cost and eco-friendly nanofluid for improving thermal performance of plate heat exchanger
}

\author{
Seyed Mohammad Sadegh Hosseini ${ }^{1}$ (D) Mohsen Mirzaei ${ }^{2}$
}

Received: 31 March 2020 / Accepted: 24 July 2020 / Published online: 23 September 2020

(c) Springer Nature Switzerland AG 2020

\begin{abstract}
Synthetic nanofluids are produced by expensive and complex procedures which hinders their large-scale application in thermal systems. In this study the montmorillonite clay as a natural nanostructure material with a high dispersion ability has been introduced for achieving low cost and eco-friendly water-based green nanofluid. For this purpose, a set of montmorillonite nanofluids (MMTNFs) with different weight fractions of $0.2,0.4,0.6,0.8$, and $1 \%$ was mechanically prepared. The concentration-dependent properties of the samples including stability, thermal conductivity and viscosity were experimentally evaluated. The results indicated that MMTNFs were accompanied by a primary instability, but they gradually possessed excellent long-term stability. Adding montmorillonite to the water could enhance thermal conductivity up to $8.3 \%$, which is worth with considering the naturalness, abundance and low-cost of this clay. MMTNFs exhibited excellent thermal performance when utilized as a working fluid instead of the pure water in a plate heat exchanger (PHE). The results showed that the best performance of PHE was obtained at an optimum MMT concentration $(0.6 \mathrm{wt} \%)$. At optimal condition, the overall heat transfer coefficient, heat transfer rate, and thermal efficiency improved $27.25 \%, 17.65 \%$, and $7.82 \%$, respectively.
\end{abstract}

Keywords Montmorillonite · Green nanofluid · Plate heat exchanger · Heat transfer · Thermal efficiency

\section{Introduction}

By scientific definition, nanofluids are colloidal suspensions of nanoparticles with size less than $100 \mathrm{~nm}$ in at least one dimension, suspended in water or other base fluids [1]. Recently, much effort of heat management has been made to save more energy through performing nanofluids to enhance the convective heat transfer of the working fluids [2]. The outstanding feature of the nanofluids is exhibited in the enhanced conductivity. In comparison with the common base fluids, the nanofluids show higher convective and conductive heat transfer coefficients. There are several physical phenomena to describe the prominent characteristic of nanofluids that their understanding can be helpful in preparing new nanofluids. Adding nanoparticles to the base fluid increases the heat transfer area, which in turn improves heat diffusion. The Brownian motion of the suspended nanoparticles is another cause of the improved properties of nanofluids, which further increases the collision in the fluid medium. The interfacial layers which play the function of a thermal bridge between liquid bulk and solid particles are a main factor for improving heat transfer. Particle aggregation and clustering as well as nanoparticles shape can also be effective in this regard $[3,4]$.

In the pursuit of improving the efficiency of the heating and cooling systems, improvement of their saving energy has been analyzed from different points of view. Hence,

Seyed Mohammad Sadegh Hosseini, m.hosseini@vru.ac.ir| ${ }^{1}$ Department of Chemical Engineering, Vali-e-Asr University of Rafsanjan, Rafsanjan, Iran. ${ }^{2}$ Department of Mechanical Engineering, Vali-e-Asr University of Rafsanjan, Rafsanjan, Iran. 
one of the most helpful applications of nanoparticles can be their use in the various mechanisms of heat transfer [5]. Heat exchangers are widely used in many engineering applications, for example, applications in chemical industry, power production, food industry, environment engineering, waste heat recovery, air conditioning, and refrigeration [6]. The increase in the number of research articles devoted to the assessment of nanofluids in the heat exchanger shows a noticeable growth and the importance of heat transfer enhancement technology. So, several studies have been focused on the application of nanofluids made of metals or metal oxides nanoparticles such as $\mathrm{CuO}, \mathrm{ZnO}, \mathrm{CeO}_{2}, \mathrm{Al}_{2} \mathrm{O}_{3}$, and $\mathrm{TiO}_{2}$ [7-11], or in some cases the nanofluids made of carbon nanostructures such as carbon nanotubes or graphene nanoplatelets [12-14]. The mentioned nanofluids could improve overall heat transfer coefficient and efficiency of the heat exchangers, whereas both nanofluids concentration and volume flow rate have strong effects on the efficiency enhancement. However, the enhancement of hydraulic characteristics, including friction factor, pressure drop and pumping power, can limit the use of nanofluids in thermal systems.

The synthetic nanomaterials are predominantly expensive (accompanied by complex and time-consuming synthesis) and can bring great costs to practical applications in industrial or even semi-industrial scale. It seems that the utilization of synthetic nanofluids does not have economic efficiency in the large-scale thermal systems. Also, some of the chemical methods for producing nanoparticles leave toxic and hazardous substances that have adverse effect on humans, animals and the environment [15]. For example, Hummers' method is a conventional chemical process that can be used normally to produce graphene oxide. This method uses various types of hazardous chemicals, including potassium permanganate, sodium nitrate and sulfuric acid [16]. In addition, synthetic nanoparticles in turns can be absorbed into the lungs through inhalation which can lead to inflammation [17]. The oxides in metal nanoparticles are able to make reactive oxygen species and this increases their toxicity.

The subject of utilizing green nanofluids or biobased nanofluids in thermal systems is evolving over time. These can reduce dimensions in heat exchangers, increase productivity, reduce fuel consumption and save costs. In addition, green nanofluids can be very helpful to the environment due to their low toxicity and availability of their precursors which are originated from nature [18]. These natural ingredients, include plant or mineral species, can directly use for preparing nanofluids with enhanced thermophysical properties without any hard chemical pre-treatments. For example, Awua et al. [19] conducted an experimental study on the preparation of nanofluids by dispersion of palm kernel fiber-based nanoparticles into a suitable base fluid. The plant-based nanoparticles obtained from the ball milling treatment. Based on their results, adding nanoparticles in the water/ ethylene glycol mixture (60:40) causes the considerable enhancement of thermal conductivity so that at $0.4 \%$ volume fraction, $18 \%$ enhancement in thermal conductivity was observed. Ranjbarzadeh et al. [20] have been introduced a green water-based silica nanofluid with high heat transfer potential in heat exchangers. The low cost production of silica nanoparticles from plant source of rice bran has been performed by them. Their results revealed that adding this eco-friendly nanoparticles to the pure water could enhanced thermal conductivity up to $38.2 \%$ at the temperature of $55{ }^{\circ} \mathrm{C}$ and solid volume fraction of $3 \%$. Essa et al. [21], conducted an experiment researching on the coffee-based colloid as an organic, low cost, and ecofriendly alternative to conventional inorganic-based nanofluids to increase the fresh water productivity of solar stills. Their results showed that the daily freshwater productivity in the nanofluid-modified system reached to $4865.73 \mathrm{ml} /$ $\mathrm{m}^{2}$ which was greater than that of the ordinary system by $35.14 \%$.

Clays have long been used as a well-known material in the old industries such as agricultural, pharmaceutical, ceramics, foundry, petroleum, bleaching and etc., because of their abundance and economic viability [22]. Nonetheless, with recent advances in nanotechnology, the new applications of clay minerals are emerging. For example, the employment of nanofluids containing fineclay particles in heat and mass transfer can be a new initiative in these area. One of the most important characteristics of the clay mineral particles is colloid stability in the aquatic environment which can be an effective property for improved transferring of heat energy within a fluid. The nature of clay colloidal systems is very complex and different from other colloidal matters due to the highly anisometric and often irregular particle shape, the different types of charges, the heterogeneity of the layer charges, the pronounced cation-exchange capacity (CEC), the flexibility of the layers, and the different modes of aggregation [23]. There are only a few studies that utilize the clay minerals for nanofluids applications. For example, Algeria et al. [24] studied the stability and thermal properties of halloysite-water nanofluids. They showed that these nanofluids had a lower Prandtl number than conventional nanofluids and could be used in thermal applications. Halloysite is an aluminosilicate clay mineral of the kaolin group with a predominantly hollow tubular structure in the submicron and nano-metrical range [25]. Chakraborty et al. [26] emphasized on the synthesis, thermal and stability characterization of $\mathrm{Cu}$-Al layered double hydroxide (LDH) water nanofluids. They discussed the influence of nanoparticle shape and nanoparticle size on 
the nanofluids thermal conductivity. The maximum thermal conductivity enhancement was reported as $16.1 \%$ for 0.80 vol\% of Cu-Al layered double hydroxide nanofluids.

Montmorillonite (MMT) is one of the most intensively explored natural nanostructure materials in nanotechnology [27]. MMT is a famous phyllosilicate from the subgroup of smectite clays, and for its unique physical and chemical properties has recently re-received more attention. Because of the abundantly and feasibility of nano-size conversion of MMT particles, it has been used as a valuable additive in nanomaterials, medicine, carrier materials and fine chemicals [28, 29]. Nevertheless, MMT has been rarely used in the advanced thermal applications and it is only used in the drilling mud for cooling operation. According to the Handbook of clay sciences [30], MMT crystals consists of three alumina and silicate layers, with a substantial amount of inherent negative charge due to isomorphic substitution. Each MMT particle can be consists of several platy layers which are arranged and compact in parallel structure, but, mostly, they are delaminated into smaller species [31, 32]. The MMT layers are grafted together through the Vander Waals forces between the compensation cations and crystal negative charge. MMT has an ability to swell in an aqueous media and water molecules can be absorbed between its layers. When the value of swelling in MMT is high (especially in the Na saturated MMT), Vander Waals forces between MMT layers weakens and due to a mechanical shear stress a highly colloidal dispersion of the MMT nanoplatelets is obtained [33]. The charge-balancing ions still remain near the surface of the sheet in a diffuse double layer. Along with the DLVO theory, the MMT particles in dilute dispersion $(<1 \mathrm{wt} \%)$ are not so affected by gravity and still continue to distance themselves because the Brownian motion can be more effective than the limiting force by gravity [34].

Due to the colloidal nature of MMT and by considering its chemical and physical properties, the present study was implemented to investigate thermal characteristics of the dilute montmorillonite dispersion as a novel, low cost and eco-friendly nanofluid for improving performance of a plat heat exchanger (PHE). In this way, the experiments performed in the conditions that the weight fraction of MMT varied by $0.2,0.4,0.6,0.8$, and $1 \mathrm{wt} \%$ and the nanofluid flow rate as a coolant fluid was constant $2 \mathrm{~L} / \mathrm{min}$ for thermal testing. In this paper, Sect. 2 provides a complete description of the experiments, including the introduction of montmorillonite as the raw material, an explanation about the methods for preparing nanofluids and their properties measurements, determining the uncertainty of the results and an expression about the heat exchanger testing. The results and related discussions about the nanofluid characterization and heat transfer are placed in
Sect. 3. In Sect. 4, the important conclusions of the present work are summarized.

\section{Experimental}

\subsection{Materials}

In our experiments, a sample of sodium montmorillonite (Na-MMT) was supplied by Department of Material Science, Institute of Science and High Technology and Environmental Sciences (Kerman, Iran). This mineral clay had already been obtained by purification of a bentonite sample through the method of Gong et al. [28]. The chemical composition of MMT, with a dry density of $2.7 \mathrm{~g} / \mathrm{cm}^{3}$, was found to be as follows: $63.8 \% \mathrm{SiO}_{2}, 16.4 \% \mathrm{Al}_{2} \mathrm{O}_{3}, 2.8 \%$ $\mathrm{Fe}_{2} \mathrm{O}_{3}, 2.6 \% \mathrm{MgO}, 0.6 \% \mathrm{CaO}, 3.1 \% \mathrm{Na}_{2} \mathrm{O}, 10 \%$ loss of ignition (LOI). The MMT sample with a high cation exchange capacity (CEC: $110 \mathrm{cmol}_{\mathrm{C}} / \mathrm{Kg}$ ) and with an inherent surface area $\left(750 \mathrm{~m}^{2} / \mathrm{g}\right)$ showed impressive colloidal ability in the water. The X-ray diffraction patterns (XRD) of MMT, gained by a diffractometer (Bruker, $\mathrm{D}_{8}$ Advance, Germany), are displayed in Fig. 1a. The results indicate 2:1 parallel structure of MMT, in which, several sodium atoms have been distributed on the silica surfaces. The value of basal spacing (d001) in the dried sample was around $1.12 \mathrm{~nm}$, while the hydrated sample showed variable basal spacing related to the hydration order. The Fourier-transform infrared spectroscopy analysis (FTIR) of MMT was performed by a spectrometer (Thermo Fisher Scientific, Nicolet iS20, USA). According to the FTIR results (Fig. 1b), a series of hydrophilic functional groups are identified in the MMT structure. The band appeared in $3629 \mathrm{~cm}^{-1}$ is ascribed to the hydroxyl groups $(-\mathrm{OH})$ coordinated to octahedral cations. The $\mathrm{OH}$ stretching vibrations of water molecules on the external MMT layer described by a broad band around $3449 \mathrm{~cm}^{-1}$. Bending vibrations of water molecules have caused a peak around $1638 \mathrm{~cm}^{-1}$. The band around $1039 \mathrm{~cm}^{-1}$, attributed to the asymmetric stretching vibrations of silica tetrahedral in the MMT structure. Three bending vibrations of hydroxyl group at $907 \mathrm{~cm}^{-1}, 873 \mathrm{~cm}^{-1}$ and $805 \mathrm{~cm}^{-1}$ are respectively linked to $\mathrm{Al}-\mathrm{Al}-\mathrm{OH}, \mathrm{Al}-\mathrm{Fe}-\mathrm{OH}$ and $\mathrm{Al}-\mathrm{Mg}-\mathrm{OH}$ [35].

The scanning electron microscopy image (SEM) of the sample, were taken from a field emission electronic microscope (Hitachi, S4160, Japan), is presented in Fig. 1c. The MMT nanoparticles are visible while they have formed several larger agglomerates. These agglomerated species can disintegrate in aqueous medium under sonication process, resulting in the stable dispersion. According to Poli et al. [36], the sonication process can change the size of MMT particles and improve their colloidal properties. 
Fig. 1 The structural specification of MMT powder; XRD pattern (a), FTIR spectrum (b), and SEM images (c)
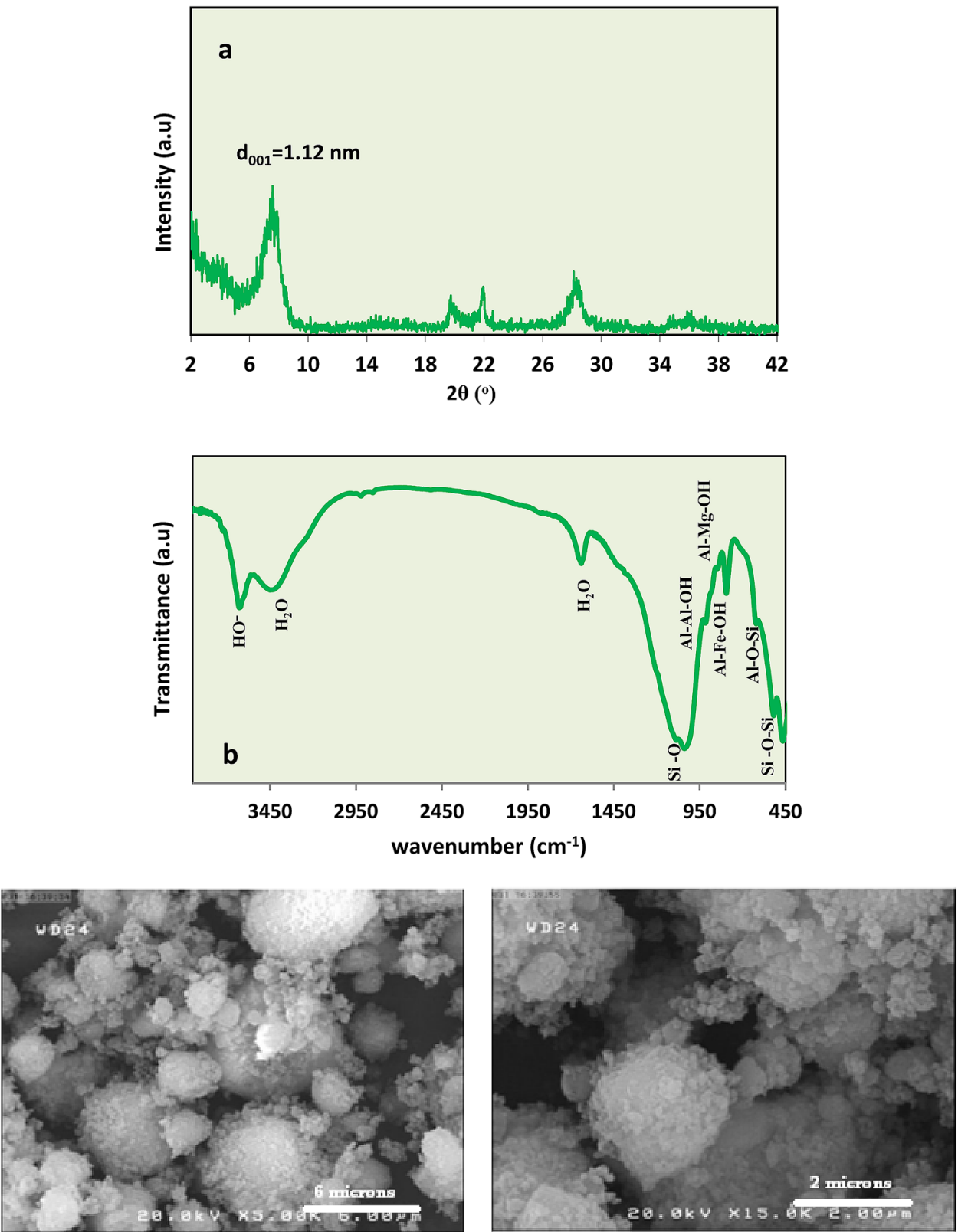

c

\subsection{Preparation of MMT nanofluid}

Making a stable nanofluid is the main challenge when engaging nanofluids [37]. Formation of agglomerates, due to the presence of attraction forces between nanoparticles, drops the thermal properties of nanofluid. It seems that MMT can overcome this problem due to its inherent colloidal power. A technique similar to the two-step method was applied in this study to prepare the waterbased MMT nanofluid.

A certain amount of the grounded MMT powder was gradually added to distilled water into a glass container. After $24 \mathrm{~h}$ aging, the swollen MMT was completely delaminated with a mechanical overhead stirrer (IKA, EUROSTAR 20, Germany) at 8000 rpm for 2 h to create plate-like species. The mixture was then affected by a probe ultrasonic (topsonic, UHP-400, Iran) at $300 \mathrm{~W}$ for $60 \mathrm{~min}$ apparatus to collapse larger agglomerates and to yield homogeneous colloidal dispersion. The used devices for preparing montmorillonite nanofluids (MMTNFs) are shown in Fig. 2a, b. Five dilute dispersions with different weight fractions of $0.2,0.4,0.6,0.8$, and $1 \mathrm{wt} \%$ were prepared which are photographically shown in Fig. 2c. The stability evaluation was tested through a spectrophotometer (Varian-Carry 100) based on the variance of light absorbed by the nanofluids. 
Fig. 2 The equipments for preparing MMTNFs; probe ultrasonic (a), and mechanical stirrer (b); digital photographs of the nanofluid samples (c)

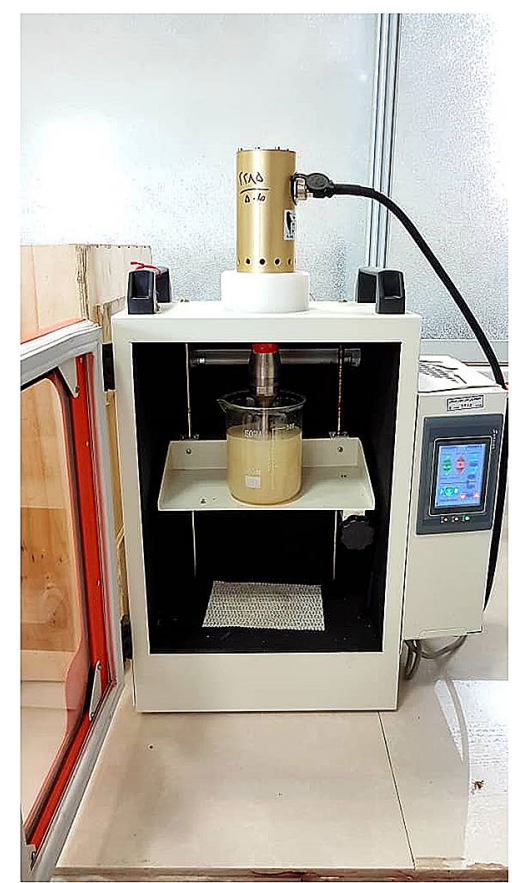

$\mathbf{a}$

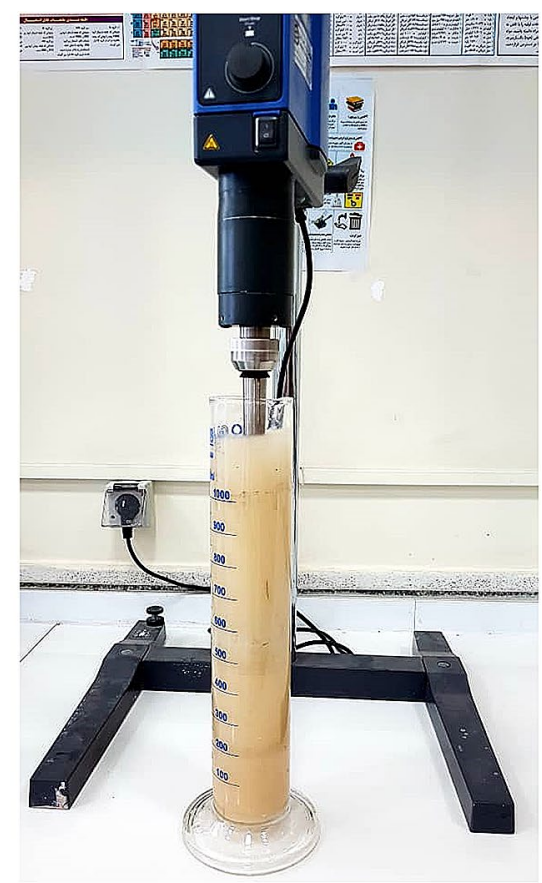

b

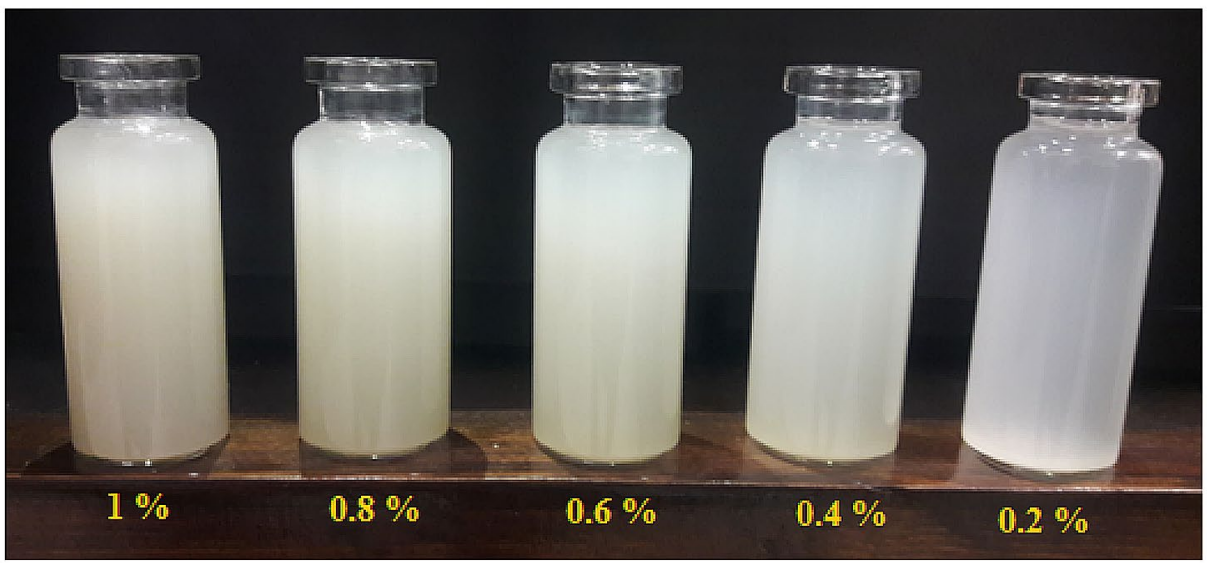

c

Thermal conductivity of nanofluids is a significant transport property for their practical application. To measure thermal conductivity of MMTNFs with the different concentration, hot-wire technique has been performed. One of the biggest advantages of this method is the almost complete elimination of natural convection due to the short measurement time, which may give rise to unwanted problems for measurements. So, a KD2 Prothermal meter with a maximum accuracy of $\pm 5 \%$ (Decagon Company, KD2 Pro-thermal, USA) was applied for thermal conductivity measurements. The instrument was equipped with a probe of $60 \mathrm{~mm}$ length and $1.3 \mathrm{~mm}$ diameter, a microprocessor and a thermoresistor to control and measure the conduction in the probe. The sample and the probe were equilibrated at a fixed temperature using a temperature-controlled bath (Fig. 3a). Thermal conductivity measurement was performed at a temperature range between 20 and $60^{\circ} \mathrm{C}$.

A viscometer (Brookfield Company, DV-I Prime, USA) was used to measure the viscosity of MMTNFs. The nanofluid temperature was set at a specified value $\left(20^{\circ} \mathrm{C}\right)$ using a refrigerated circulating bath (Fig. $3 \mathrm{~b}$ ). The measurements were performed at a constant shear rate and a constant temperature, while the MMT weight fraction varied by $0.2,0.4,0.6,0.8$, and $1 \%$. Three measurements 
Fig. 3 The schematic diagram of thermal conductivity and viscosity measurements a

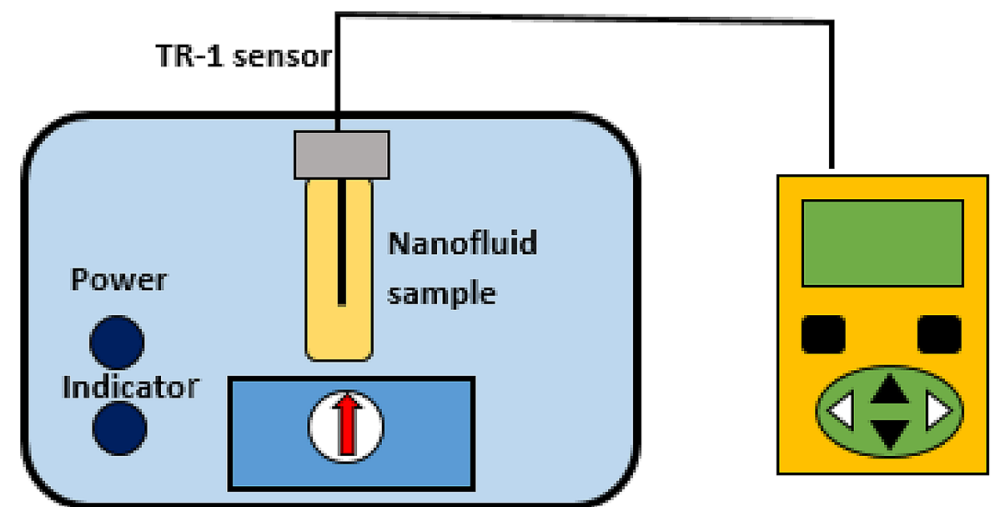

Temperature-controlled bath

$\underline{\mathbf{b}}$

Brookfield viscometer

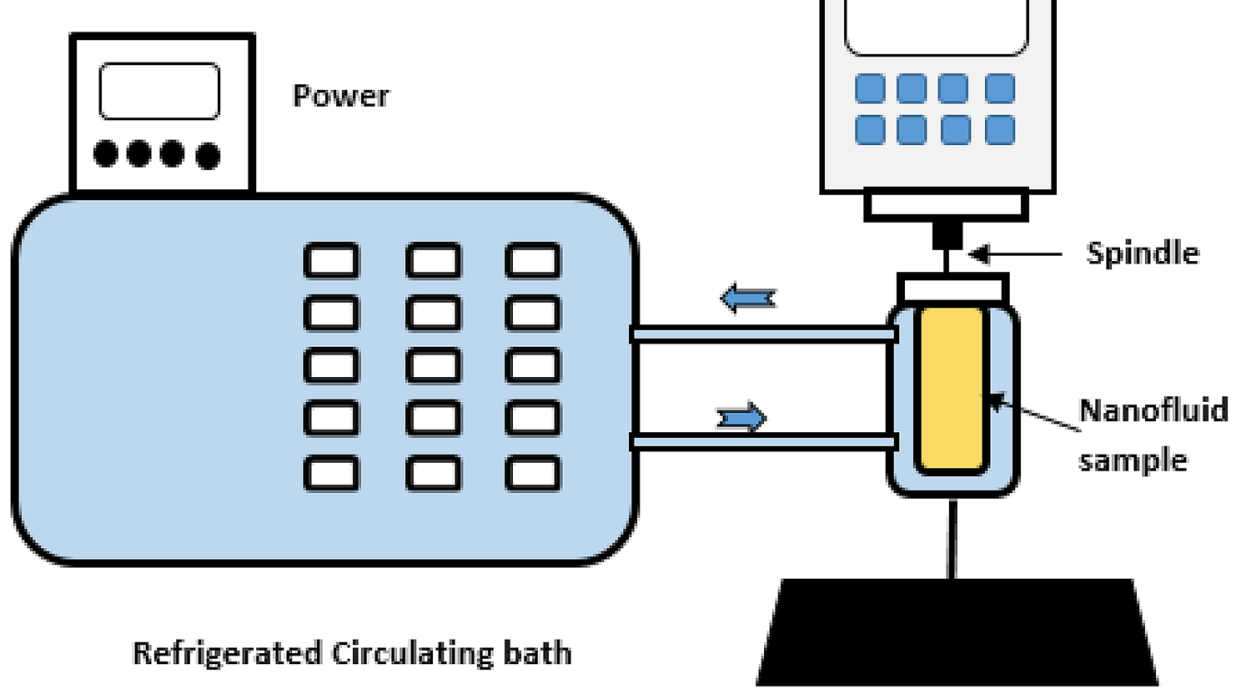

were obtained for each test and the maximum uncertainty of viscosity was found to be around $3.2 \%$.

A UV/Visible spectrophotometer (Shimadzu, 12002 , Japan), that equipped by deuterium and tungsten lamps, was verified for measuring the concentration of nanofluid samples at different times. The experiments were done in the wavelength range of $200-800 \mathrm{~nm}$ at $20^{\circ} \mathrm{C}$. The pure water was employed as a control sample, and a quartz cell was used as a small tube-like container to hold samples for the measurements.

Also, particle size distribution in the nanofluid samples was examined using dynamic light scattering (DLS) (Malvern Instrument, ZEN3600, UK). This measurement was performed at 20 and $40^{\circ} \mathrm{C}$.

\subsection{Experimental heat transfer setup and procedure}

The thermal setup focusing on plate heat exchanger is shown in Fig. 4a, while Fig. 4b presents the schematic diagram of the given test setup. The plate heat exchanger (PHE) consisted of 15 plates (stainless steel 316) with a theoretical gap of $2.5 \mathrm{~mm}$ among each two plates, $0.5 \mathrm{~mm}$ thickness of plates, and $0.21 \mathrm{~m}^{2}$ surface of heat transfer. MMTNFs as a cold stream and pure water as a hot fluid were passing through PHE in a closed loop by two centrifugal pumps. The flow rate of hot and cold fluid flows has been gauged by two rota-meters, and the volume flow rates have been adjusted through the gate valves. PHE operated in counter current mod. The inlet and outlet temperatures of working fluid flow 


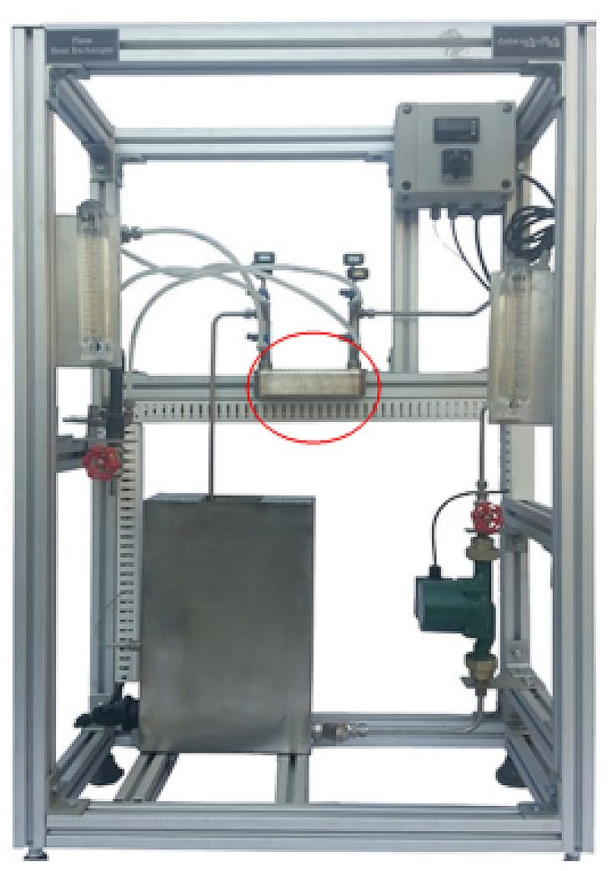

$\mathbf{a}$

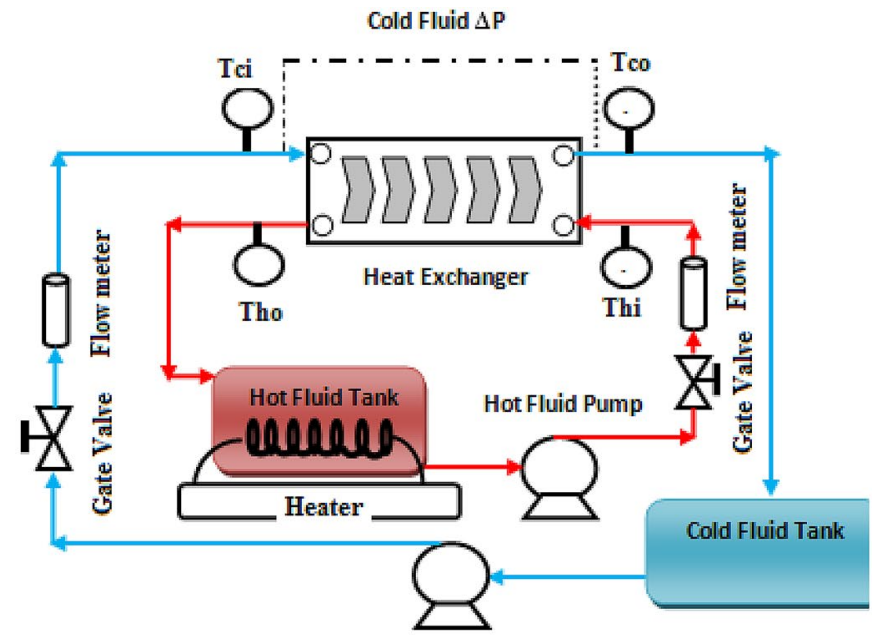

b

Fig. 4 The experimental set up of thermal system (a), the schematic diagram of process (b)

are measured through four calibrated digital thermometers (Lutron, TM-917, Taiwan). The desired set point temperatures for the cold and hot streams are respectively considered 20 and $60^{\circ} \mathrm{C}$. The nanofluid as a coolant working fluid flows through PHE which its pressure drop was determined by a differential manometer. The hot stream (water) after cooling by the nanofluid, come back to the bath tank with an immersed heater $(3 \mathrm{~kW})$ to reheat and reach to the initial set temperature. A thermostat in a control box is utilized to keep the temperature of fluid in tank near a desired set point. At the beginning of the experiment, the heaters inside the reservoir are tuned on until the temperature of water inside the tank reach to a set-point value. Then a centrifuge pump, coupled with adjusted valve, circulates the hot flow in the PHE. Simultaneously, the cold nanofluid is pumped and adjusted to a specified volume flow rate.

The volume flow rate of hot and cold flow is fixed at $2 \mathrm{~L} /$ $\mathrm{min}$. The experimental observation shows that after $25 \mathrm{~min}$, the thermal system reached to the steady state conditions, afterwards the data are recorded. To improve the accuracy of experiments, reproducibility of experimental data for all tests have been checked via three successive runs of experiments. According to the accuracy of the equipment and repeatability of experiment, the acquired uncertainty has been considered by $95 \%$ confidence level.

\subsection{Data analysis}

The heat capacity and density of MMTNFs can be observed in the laboratory tests, while they can be also calculated through following equations [38].

$\rho_{n f}=\varphi \cdot \rho_{n p}+(1-\varphi) \cdot \rho_{b f}$

$c_{p_{n f}}=\frac{(1-\varphi)\left(\rho_{b f} C_{p_{b f}}\right)+\varphi\left(\rho_{n p} C_{p_{n p}}\right)}{\rho_{n f}}$

where " $\rho$ " is density and " $C_{p}$ " is specific heat of fluids, and " $\varphi$ " represents the nanoparticles volume fraction (vol\%). The overall heat transfer coefficient of PHE is obtained through driving the energy balance between the hot and cold fluid flows by neglecting the heat losses to ambient as follows [10]:

$q_{c}=\dot{m} C_{p, c}\left(T_{c, o}-T_{c, i}\right)$

$q_{h}=\dot{m} C_{p, h}\left(T_{h, o}-T_{h, i}\right)$

$q_{a v}=\frac{\left(q_{h}+q_{c}\right)}{2}$ 
In the above Eqs, " $\mathrm{q}_{\mathrm{h}}$ " and " $\mathrm{q}_{\mathrm{c}}$ " present the thermal energy removed from hot steams (nanofluids) and thermal energy absorbed by the cold steams (water), respectively. The average value of heat exchanging between hot and cold steams are shown by " $\mathrm{q}_{\mathrm{av}}$ ". The cold and hot fluid mass flow rates are respectively shown in " $\dot{m}_{c}$ " and " $\dot{m}_{h}$ ".

Thermophysical properties of water and MMTNFs were measured at the mean temperature.

$T_{m, c}=\left(T_{c, o}+T_{c, i}\right) / 2$

$T_{m, h}=\left(T_{h, o}+T_{h, i}\right) / 2$

According to the average heat transfer between the heating and cooling loops, geometry of PHE and the stream temperatures at inlet and outlet, the overall heat transfer coefficient is obtained by following equations.

$U=\frac{q_{\text {ave }}}{A \cdot L M T D}$

where, " $A$ " shows the total surface area of plates of heat exchanger, " $\triangle \mathrm{T}_{\mathrm{LMTD}}$ ", presenting the logarithmic mean temperature difference, is calculated using Eq. (9).

$\Delta T_{\text {LMTD }}=\frac{\left(T_{h, o}-T_{c, i}\right)-\left(T_{h, i}-T_{c, o}\right)}{\ln \left[\frac{\left(T_{h, o}-T_{c, i}\right)}{\left(T_{h, i}-T_{c, o}\right)}\right]}$

Based on the fixing of the inlet temperatures $\left(T_{c, i}\right.$ and $\left.T_{h, i}\right)$ to be 20 and $60^{\circ} \mathrm{C}$, the thermal efficiency of PHE can be presented with the below equation.

$\Delta=\frac{q_{\text {ave }}}{q_{\max }=\left(\dot{m} c_{p}\right)_{\min }\left(T_{h i}-T_{c i}\right)}$

The pump power was obtained by Eq. 11, in which, the pressure drop is presented as " $\Delta P_{n f}$ "

$\mathcal{P}=\frac{\dot{m}_{n f}}{\rho_{n f}} \cdot \Delta P_{n f}$

\subsection{Uncertainty Analysis in the thermal system measurements}

In an experimental study, errors and uncertainties are inherent in both the instrument and the measurement process. They can arise from different ways, among them can mention instrument selection, condition, calibration, environment, observation, reading and test planning [39]. Uncertainty analysis of the experimental measurements, which deals with the prediction of the uncertainty interval,
Table 1 The uncertainties through the measurements of the experimental parameters

\begin{tabular}{ll}
\hline Description & $\begin{array}{l}\text { Uncer- } \\
\text { tainty } \\
\text { value (\%) }\end{array}$ \\
\hline Temp. of hot flow (inlet) & \pm 1.5 \\
Temp. of hot flow (outlet) & \pm 1.5 \\
Temp. of cool flow (inlet) & \pm 1.5 \\
Temp. of cool flow (outlet) & \pm 1.5 \\
MMTNFs vol. flow rate & \pm 2.5 \\
Water vol. flow rate & \pm 2.5 \\
\hline
\end{tabular}

is performed to estimate reliability of the empirical tests. Especially, the measurements in this work are performed for calculating the thermal characteristics of the heat exchanger. The general form of uncertainty analysis is presented in Eq. 10. In this equation " $W_{y}$ " shows the total uncertainty of the independent calculated parameter and "Wxi" is the root sum square of scatter uncertainty of each measured parameter.

$W_{y}^{2}=\sum_{i=1}^{n} W_{x_{i}}^{2}$

The uncertainty in calculating of the main heat transfer parameters is obtained by the values presented in Table 1 with assuming negligible errors in " $C_{p}$ " and " $\rho$ ". Based on Eq. 10, the maximum uncertainty in the given experiment for determination of the heat transfer rate, overall heat transfer coefficient and PHE thermal efficiency are $\pm 3.6 \%, \pm 3.4 \%$, and $\pm 3.4 \%$, respectively.

\section{Results and discussion}

The present experiment is described in two sections to evaluate the thermal potential of MMTNFs. The first one leads to the characterization of MMTNFs through thermal conductivity and dynamic viscosity, as well as colloidal stability. The second one relates to the heat transfer characteristics of MMTNFs and the optimal concentration is presented to attain maximum performance of PHE. This study concentrates on the effect of MMT concentration on the overall heat transfer coefficient, thermal efficiency and pumping power.

\subsection{Characterization of MMTNFs}

Ultraviolet-visible spectroscopy is a developed analytical technique for the qualitative and quantitative 
Fig. 5 The UV-Vis absorption results (a), the nonlinear curve between MMT concentration and the $\lambda_{\max }$-absorption (b), the concentration of MMTNFs versus aging time $(\mathbf{c})$
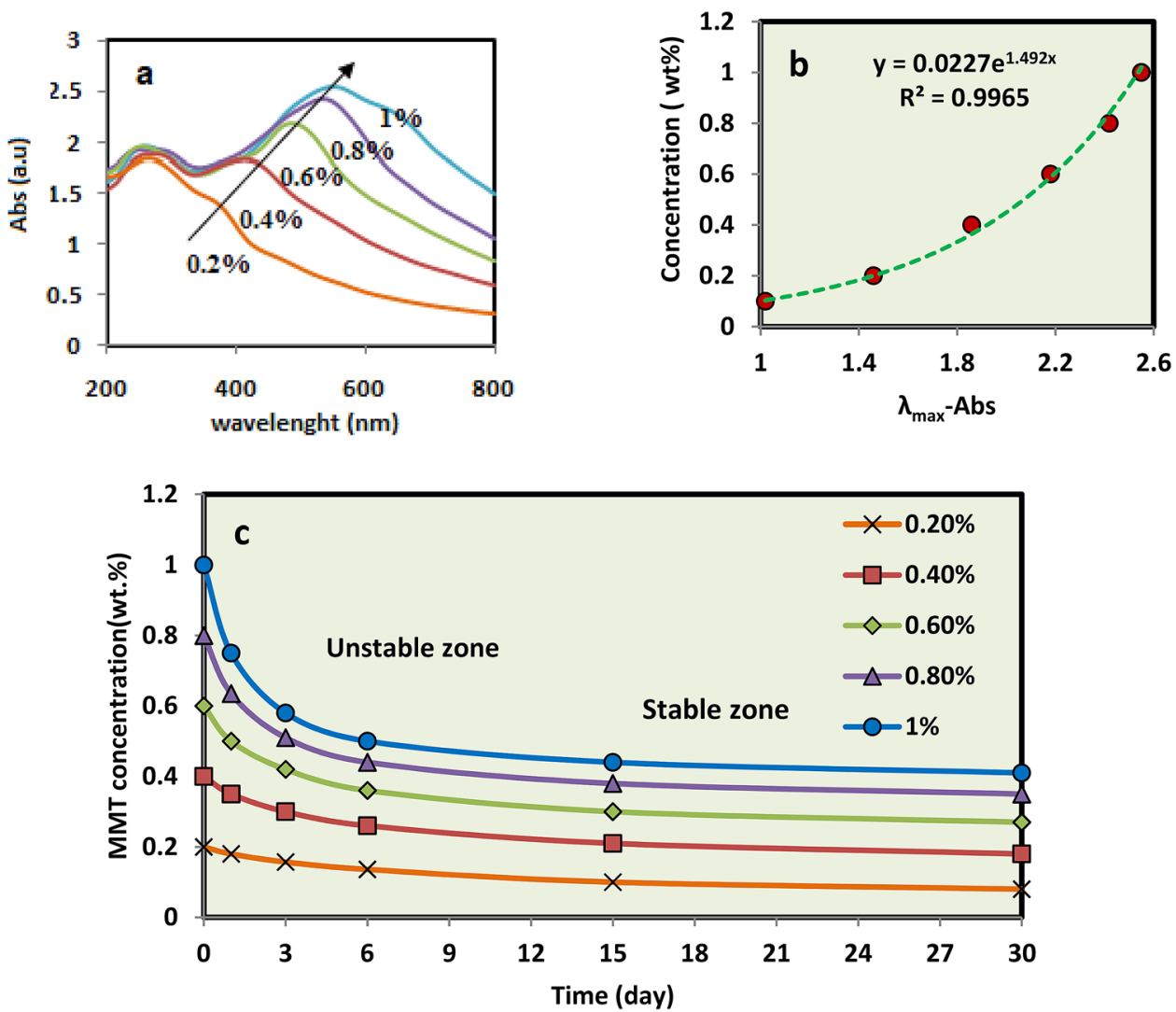

characterization of colloidal dispersions [40]. The UV-visible absorption results of MMTNFs are illustrated in Fig. 5 a. Reasonably, a high value of light absorption is obtained by concentrated dispersion ( $1 \mathrm{wt} \%$ ) due to the more suspended particles. There is an obvious absorption behavior in MMTNFs spectra which related to the surface transitions [41]. The absorption peak located about $300-600 \mathrm{~nm}$ is highly dependent on the MMT concentration. It will become stronger and red-shift specifically from $367 \mathrm{~nm}$ to $551 \mathrm{~nm}$ as the initial concentration value increase from $0.2 \%$ to $1 \%$. This absorption characteristic cannot be described by Beer-Lambert theory which is likely due to turbid nature of the dispersions. Figure $5 b$ shows the high ordered-correlation between the solid concentration and the $\lambda_{\max }$-absorption. It can be used to estimate the concentration of a nanofluid at different aging time. Hence, this nonlinear absorption model was utilized to study the nanofluid stability.

The time-dependent concentration of MMTNFs, resulted from the UV-Vis data, are illustrated in Fig. 5c. These results gained $1,3,6,15$ and 30 days after preparation of the primary dispersion and were applied to stability analysis. The stability behaviors of the dispersions are nearly similar and divided into two different zones. In the time range between 1 to 6 days, the solid concentration is moderately decreased (unstable zone), and it gradually tended to a constant value between 6 to 30 days (stable zone). It is concluded that until the sixth day the denser and larger MMT species are precipitated and removed from the colloidal system. After this date, the particle sedimentation has not occurred, and the fine suspended particles approximately remained stable even 30 days (or more) after preparation of the nanofluid. A sample of the stabilized dispersion (with the initial concentration of 1 $w t \%)$ was intended for DLS analysis to evaluate the particle size distribution (PSD).

Dynamic light scattering (DLS) is a well-known technique for measuring the size and size distribution of particles typically in the submicron region. Typical applications of dynamic light scattering are the characterization of particles which have been dispersed or dissolved in a liquid. The Brownian motion of particles in suspension causes laser light to be scattered at different intensities. Analysis of these intensity fluctuations yields the velocity of the Brownian motion and hence the particle size using the Stokes-Einstein relationship. 
The result of DLS analysis at $20^{\circ} \mathrm{C}$ are shown in Fig. 6 a. The size of suspended particles in the stabilized nanofluid (with the initial concentration of $1 \mathrm{wt} \%$ ) after 30 days of preparation is approximately less than $100 \mathrm{~nm}$ and the particle size distribution (PSD) is appeared as a monomodal shape. This result proves that the ultrasonic waves has broken the MMT agglomerates and it has been quite effective in producing the very fine species.

Furthermore, the PSD of stabilized MMT nanofluid at $40^{\circ} \mathrm{C}$ is also presented in Fig. $6 \mathrm{~b}$. Unlike lower temperature, the suspended particles in the nanofluid show a coarser and bimodal distribution at higher temperature. With increasing temperature, the inter-particle attraction (Van der Waals force) between single particles (with
Brownian motion) increases. As a result, the particles are partially aggregated and form the stable larger clusters.

The dynamic viscosities of the clay-water systems (at $20^{\circ} \mathrm{C}$ ) are respectively presented in Fig. $7 \mathrm{a}$ and Fig. $7 \mathrm{~b}$. The viscosity of nanofluids increases with increasing MMT weight fraction and its value gradually rises two times that of the water. According to Lagaly and Liu [42, 43], the behavior of sodium MMT dispersions at concentrations above $2.5 \mathrm{wt} \%$ is non-Newtonian and starts to have yield strength. Although, below this concentration (the range of concentrations in this study), the MMT dispersions are Newtonian fluids and show a linear relationship between the shear stress and the rate of shear.

Thermal conductivity of MMTNFs (Fig. 7c, d) shows directly a growth with the increasing MMT concentration.
Fig. 6 The PSD in the stabilized nanofluid at $20^{\circ} \mathrm{C}(\mathbf{a})$, and 40 ${ }^{\circ} \mathrm{C}$ (b)
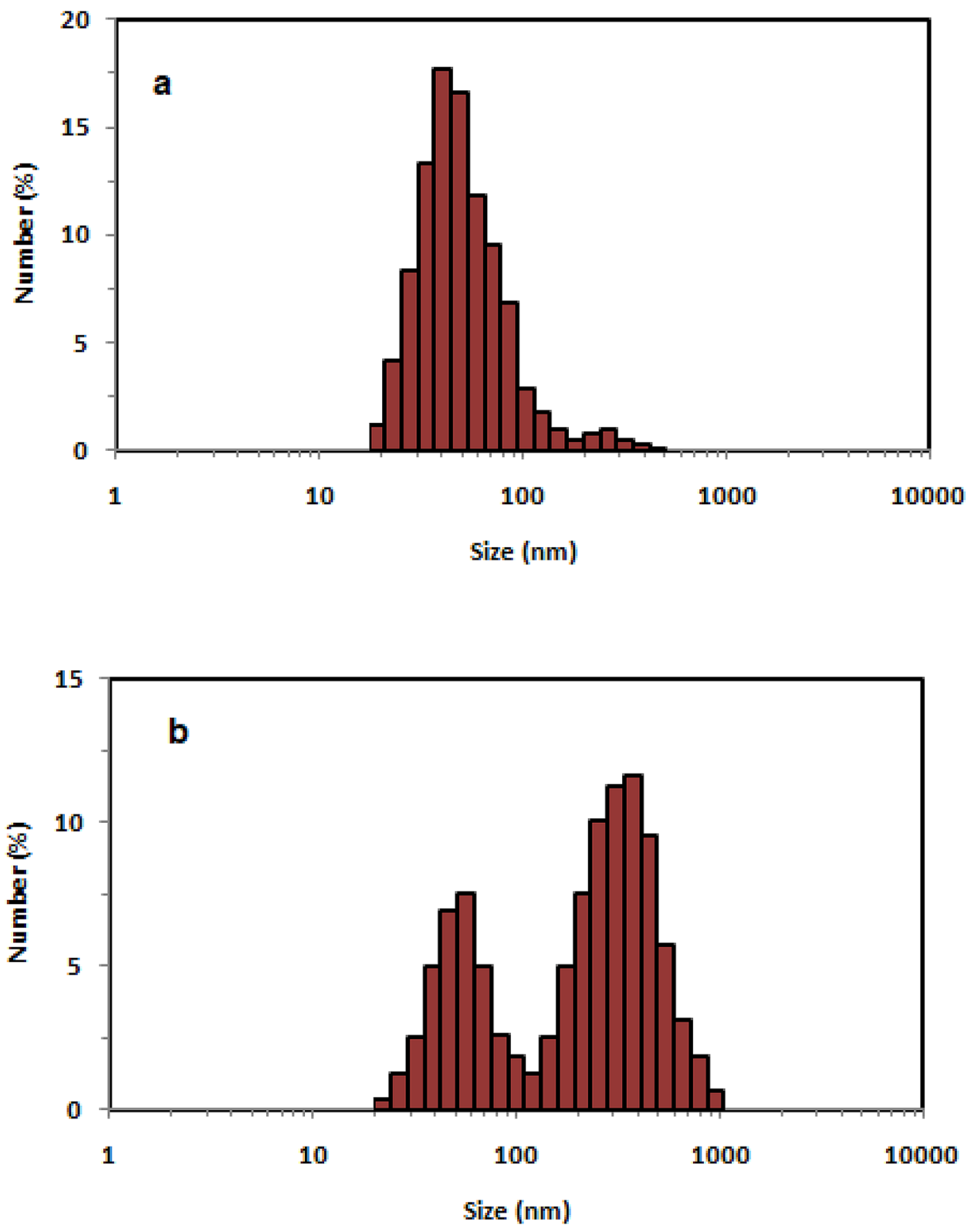
Fig. 7 The thermal conductivities (a, b), dynamic viscosities (c, d), and temperaturedependent thermal conductivities of MMTNFs (e)
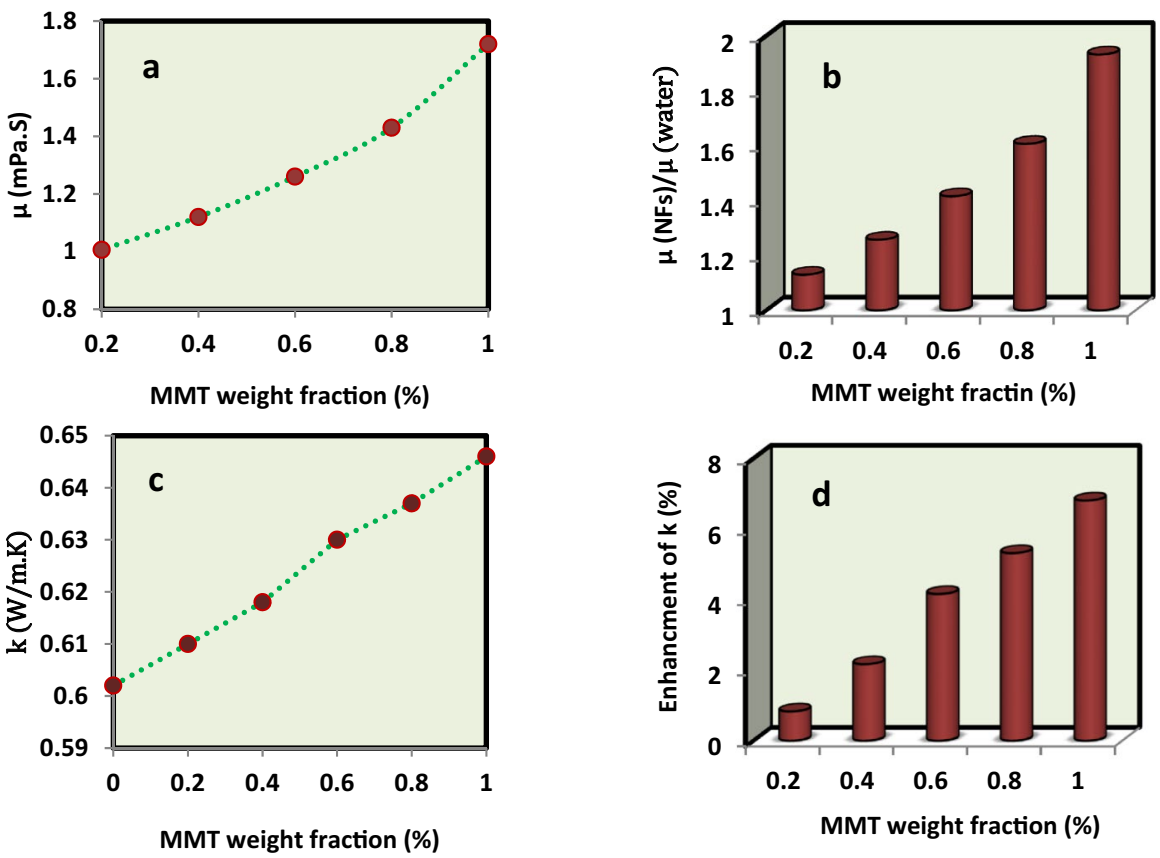

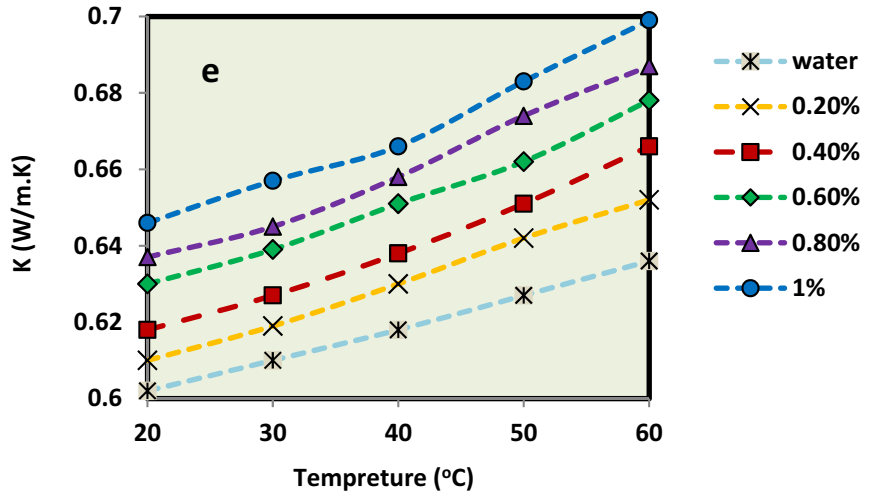

Related to the pure water as a base fluid, the maximum enhancement of thermal conductivity is obtained $6.8 \%$ at $20^{\circ} \mathrm{C}$. There are several significant parameters that having a role for enhancing thermal conductivity. According to the physics of nanofluids, thermal conductivity is mainly affected by the particles-particles collision due to Brownian motion. In the higher concentrations, more interactions between higher and lower temperature particles are happen, which result to the additional heat diffusion [44].

In addition to the Brownian motion, the interfacial layer is also discussed as a surface phenomenon for the describing nano-scale heat convection. In a solid-liquid dispersion, some of the fluid molecules loop around the solid particle to form an inseparable layer that is always moving with the particle. This thin layer acts as a thermal bridge between the solid particles and bulk liquid [45]. The effects of interfacial layer are very considerable, when the surface area of the nanoparticles is very large [46]. According to Min et al. [47], a montmorillonite particle can acquire complete or partial hydration shells due to the type of interlayer cations. Meanwhile, these hydration shells can be a good thermal intermediate on the clay-water systems. Accordingly, the plate-like MMT particles with having a high surface area and strong interfacial layer exhibit a good potential for enhancing water thermal conductivity. On the other hand, Hamilton and Crosser model interprets that the elongated particles, with specified shape factor, are more capable than that for spherical ones for improving base fluid conductivity [48]. According to Ghosh et al. [49], the enlarged aspect ratio of suspended nanoparticle increases interaction 
Table 2 The thermal conductivity enhancement of MMTNFs with different MMT weight fractions at various temperatures

\begin{tabular}{llllll}
\hline Temperature & \multicolumn{5}{c}{ Thermal conductivity enhancement (\%) } \\
\cline { 2 - 6 } & $0.2 \%$ & $0.4 \%$ & $0.6 \%$ & $0.8 \%$ & $1 \%$ \\
\hline 20 & 1.33 & 2.65 & 4.65 & 5.81 & 7.30 \\
30 & 1.47 & 2.78 & 4.75 & 5.73 & 7.70 \\
40 & 1.94 & 3.23 & 5.33 & 6.47 & 7.76 \\
50 & 2.39 & 3.82 & 5.58 & 7.49 & 8.93 \\
60 & 2.51 & 4.71 & 6.60 & 8.01 & 9.90 \\
average value & 1.93 & 3.44 & 5.38 & 6.7 & 8.32 \\
\hline
\end{tabular}

area and persuades improved heat transfer rate due to the inter-particle collision. This is another possible reason following the superior thermal conductivity of MMTNFs over a base fluid.

Figure 7e displays the effect of temperature on the thermal conductivity of MMTNFs. The thermal conductivity of MMTNFs increases almost linearly as the temperature increases from $20^{\circ} \mathrm{C}$ to $60^{\circ} \mathrm{C}$. For example, the thermal conductivity of a sample increases from $0.631 \mathrm{~W} / \mathrm{m} . \mathrm{K}$ to $0.678 \mathrm{~W} / \mathrm{m}$.K at the loading of MMT as $0.6 \%$. The reason for the enhancement in thermal conductivity may be ascribed to the clustering that previously proved in the DLS results (Fig. 6b). Nanoparticle clustering is another mechanism that has been reported for interpreting heat transfer in nanofluids [50,51]. High temperature contributes to the modified clustering of the particles. These modified species create a low thermal resistance pathway in the mixture and consequently increase thermal conductivity. The given temperatures for this measurement was approximately adjusted near to the operating temperatures in the PHE. A summary of the thermal conductivity enhancement of MMTNFs with different weight fractions at various temperatures is illustrated in Table 2.

The average enhancements in thermal conductivity between 20 to $60{ }^{\circ} \mathrm{C}$ are $1.93 \%, 3.44 \%, 5.38 \%, 6.7 \%$, and $8.32 \%$ for the nanofluids with $0.2 \%, 0.4 \%, 0.6 \%, 0.8 \%$ and $1 \%$ solid concentration.

\subsection{Heat transfer results}

The heat transfer results based on a brazed plate heat exchanger are presented in Fig. 8. Data were gotten for MMTNFs (cold fluid) and water (hot fluid) flow in the PHE in a counter current flow. The concentration of nanofluid is investigated as an operational variable to understand the optimal value of this parameter. The experiment was carried out in the concentrations range of $0.2,0.4,0.6,0.8$, and $1 \mathrm{wt} \%$ with constant nanofluid and water volume flow rate $(2 \mathrm{~L} / \mathrm{min})$. The nanofluids were used in the cold unite of the exchanger in order to improve heat transfer rate and to improve the efficiency of the heat exchanger.
As shown in Fig. 8a, the heat transfer rate (q) of MMT$\mathrm{NFs}$, with enhanced thermal conductivity, is higher than that of the pure water. The plate-like MMT nanoparticles with random movement hit the plate wall and exchange heat through mixing back with the bulk of the fluid. This action improves the heat transfer between wall and fluid. The notable behavior in the heat transfer results could be linked to the overall heat transfer coefficients (Fig. 8b), as well as thermal efficiency (Fig. 8c).

It is observed two different behaviors in the concentration-dependent thermal characteristics. In the range between 0.2 to $0.6 \mathrm{wt} \%$, the heat transfer rate, the overall heat transfer coefficient and the thermal efficiency show an increasing trend. As mentioned, Brownian motion has been suggested as a reason behind thermal enhancement in the MMT nanofluids. The increasing solid concentration ( 0.1 to $0.6 \mathrm{wt} \%$ ) leads to the more collisions between the nanoparticles and the randomly moving molecules of water.

However, at concentration above $0.6 \mathrm{wt} \%$ the results in Fig. 8 display a downside direction. In fact, the $0.6 \%$ solid weight fraction is an optimum concentration for MMTNFs to provide maximum thermal performance in the PHE. As summarized in Table 3, the maximum enhancement in $U, q$, and $\varepsilon$ at optimal concentration are about $27.25 \%$, $17.65 \%$, and $7.82 \%$, respectively.

The decrease in thermal performance at concentrations above $0.6 \mathrm{wt} \%$ could be due to the particle depositing that is more pronounced in the concentrated samples. During continues heat transfer testing, the larger solid phase species are deposited on the heat transfer surfaces, which leads to an increase in thermal resistance. This fouling condition is noticeable in the denser nanofluids which lead to decrease their thermal efficiency. Besides, the deposited layer also reduces the flow cross sectional area that results in the growth of pressure drop and pumping power. Additionally, density and viscosity of a fluid are the main parameter for the increment of pressure drop and pumping power in the internal flows. Figure 9 shows the variation of pumping power in the thermal system against solid weight fraction. As it is seen, the growth of pumping power is slowly increasing with the increase of concentration up to $0.6 \mathrm{wt} \%$. After this, the pumping power exponentially rises. For example, the power required for pumping $1 \mathrm{wt}$. \% MMTNFs is approximately seven times greater than that of the pure water. Therefore, the MMT concentration beyond the thermal optimum value (i.e. $w t \%>0.6$ ) should be avoided. Because, it is not economically applicable and will cause to severe pumping power without benefitting thermal performance. The similar trend, related to $\mathrm{ZnO}$ /water nanofluid, was also reported by Kumar et al. [52]. They showed that with increasing nanofluid concentration, along with heat transfer increments (desirable), 

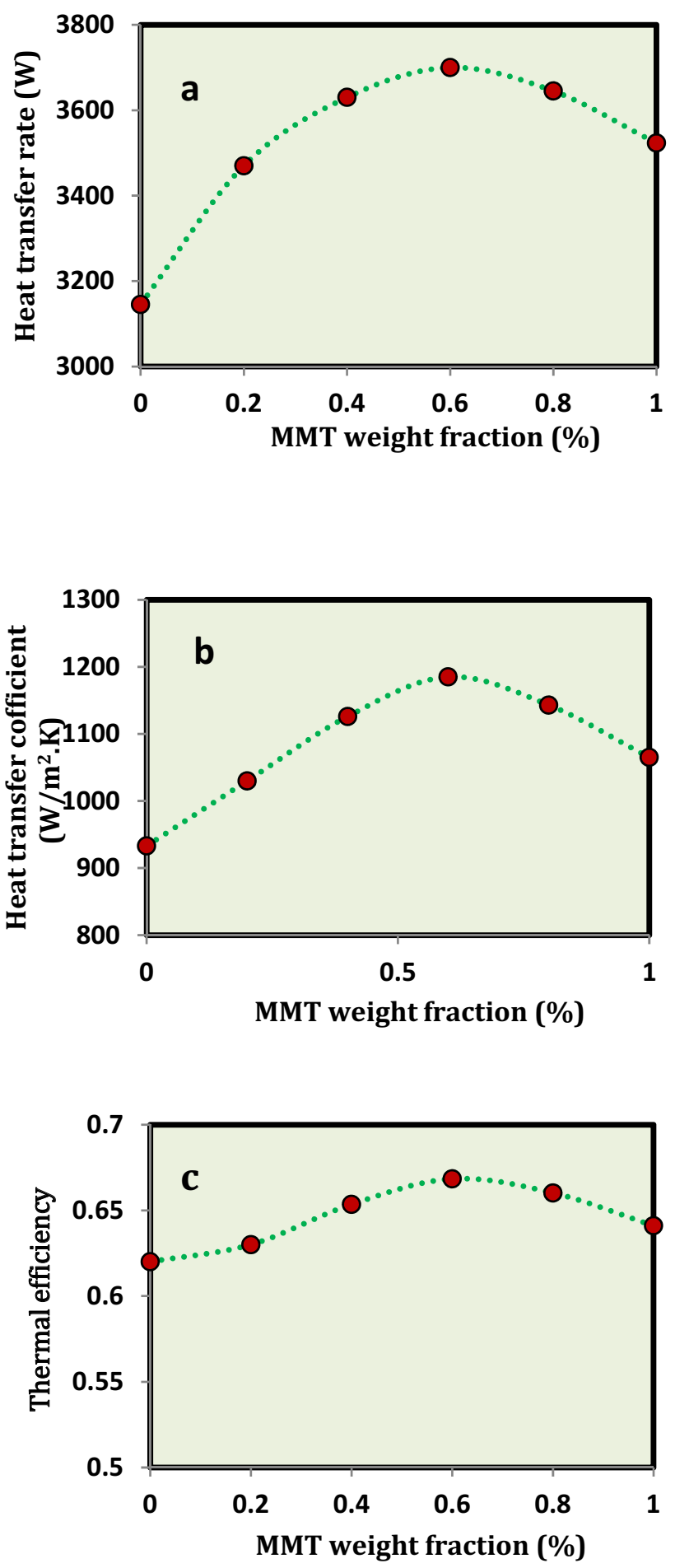

Fig. 8 Thermal performance of MMTNFs as coolant working fluid in a PHE, flowrate: $2 \mathrm{~L} / \mathrm{min}, \mathrm{T}_{\mathrm{ci}}=20^{\circ} \mathrm{C}$ and $\mathrm{T}_{\mathrm{hi}}=60^{\circ} \mathrm{C}$

the pumping power in their thermal system also increased (undesirable).
Table 3 The values of enhancement in the PHE performance characteristics with the help of MMTNFs

\begin{tabular}{llll}
\hline $\begin{array}{l}\text { MMT weight fraction } \\
\text { (wt\%) }\end{array}$ & \multicolumn{3}{l}{ Enhancement (\%) } \\
\cline { 2 - 4 } & $\mathrm{q}$ & $\mathrm{U}$ & $\varepsilon$ \\
\hline 0.2 & 10.33 & 10.40 & 1.51 \\
0.4 & 15.42 & 20.68 & 5.41 \\
0.6 & 17.65 & 27.25 & 7.82 \\
0.8 & 15.90 & 22.50 & 6.48 \\
1 & 12.02 & 14.15 & 3.39 \\
\hline
\end{tabular}

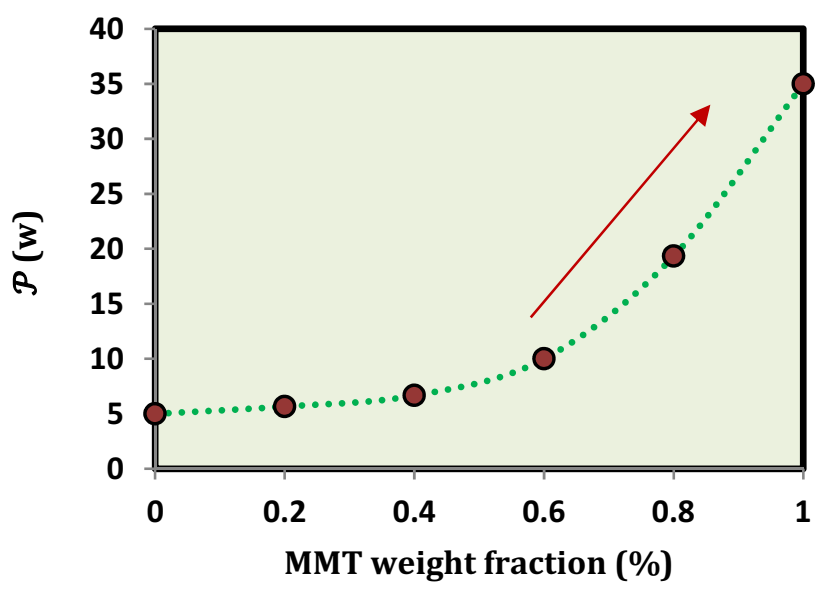

Fig. 9 The variation of pumping power versus MMT weight fraction at flow rate of $2 \mathrm{~L} / \mathrm{min}, \mathrm{Th}_{\mathrm{i}}=60^{\circ} \mathrm{C}$ and $\mathrm{T} \mathrm{c}_{\mathrm{i}}=20^{\circ} \mathrm{C}$

The summary of the best published experimental works on the nanofluids application in plate heat exchangers are illustrated in Table 4. Their experimental flow regime $(\operatorname{Re}<1000)$ corresponds to the flow-rate tested in this work. In addition, the up-to-date prices of the used nanoparticles have been extracted from Sigma-Aldrich Company.

Carbon nanomaterials appear to leave the best thermal efficiency related to other nanoparticles, while the cost of fabricating these materials even in a low concentration is very high. For example, the price of one gram of high purity graphene is about 522 EUR which makes it a great challenge to use widely. The position of the montmorillonite nanofluids in thermal performance is nearly identical to the metal or metal oxide nanofluids. By considering the price of nanomaterials, it is found that the low cost MMT nanofluid is a more economical candidate than other nanofluids to operate on the large-scale applications. Moreover, unlike synthetic nonmaterial, montmorillonite is a natural clay found in abundance in the ground. 
Table 4 The summary of the best published experimental works on the nanofluids application in plate heat exchangers, (the Table is sorted by the price of the used nanoparticles)

\begin{tabular}{|c|c|c|c|c|c|c|}
\hline Ref. & Geometry & Base fluid & NPs materials & NPs concentration & $\begin{array}{l}\text { Maximum enhance- } \\
\text { ment in heat trans- } \\
\text { fer (\%) }\end{array}$ & $\begin{array}{l}\text { NPs Price } \\
\left(^{(E U R / g}\right)^{a}\end{array}$ \\
\hline [14] & $\begin{array}{l}\text { Miniature } \\
\text { PHE }\end{array}$ & $\begin{array}{l}\text { Ethylene glycol- } \\
\text { water }\end{array}$ & Graphene & $0.01-1$ wt $\%$ & $\begin{array}{c}30 \% \text { in convection } \\
\text { heat coefficient }\end{array}$ & 522 \\
\hline [13] & $\begin{array}{l}\text { Identical } \\
\text { PHE }\end{array}$ & Water & CNTs & $0-1$ vol\% & 50 & 156 \\
\hline [53] & $\begin{array}{l}\text { Plate and fin heat } \\
\text { exchanger }\end{array}$ & Water & $\mathrm{Cu}$ & $0-0.4$ vol\% & 24 & 14 \\
\hline [11] & $\begin{array}{l}\text { corrugated } \\
\text { PHE }\end{array}$ & Water & $\mathrm{CeO}_{2}$ & $0.5-3$ vol $\%$ & 39 & 8 \\
\hline [8] & $\begin{array}{l}\text { Miniature } \\
\text { PHE }\end{array}$ & Water & $\mathrm{CuO}$ & $0-4$ vol\% & 29 & 6 \\
\hline$[54]$ & $\begin{array}{l}\text { Corrugated } \\
\text { PHE }\end{array}$ & Water & $\mathrm{Al}_{2} \mathrm{O}_{3}$ & $2-4$ vol\% & 9.43 & 3 \\
\hline [9] & PHE & Water & $\mathrm{ZnO}$ & 0.5 vol $\%$ & 14.1 & 3 \\
\hline [12] & $\begin{array}{l}\text { Commercial } \\
\text { PHE }\end{array}$ & Water & $\mathrm{TiO}_{2}$ & $0.25-0.8$ wt $\%$ & 21 & 2.4 \\
\hline In this study & Brazed PHE & Water & MMT & $0.2-1$ wt $\%$ & 17.65 & 0.12 \\
\hline
\end{tabular}

${ }^{\mathrm{a}}$ The price of nanoparticles is extracted from Sigma-Aldrich Company (2020/02/03)

\section{Conclusion}

The aim of this study is to examine the feasibility of using sodium montmorillonite as a natural and low-cost nanostructure material for preparing water-based green nanofluid to use in a plate heat exchanger (PHE). Unlike synthetic nanomaterials, which produced by the release of toxic and hazardous chemicals, the MMT clay derived directly from natural ores and are biocompatible. The plate-like MMT nanoparticles were dispersed in water by sonication treatment. In this study, five colloidal dispersions with the MMT weight fractions of $0.2,0.4 .0 .6,0.8$, and $1 \mathrm{wt} \%$ were prepared and employed for the heat transferring experiments. The results showed that MMTNFs reach a relative stability over time after passing through the initial transience. MMTNFs had different thermo-physical properties than that the pure water, where their concentration was an important parameter. As MMT concentration increased, the viscosity and thermal conductivity of MMTNFs exponentially and linearly increased. The temperature had a significant effect on the modified clustering of MMT species which led to the growth of thermal conductivity of MMTNFs. The average enhancement in thermal conductivity between 20 and $60^{\circ} \mathrm{C}$ were $1.93 \%, 3.44 \%, 5.38 \%, 6.7 \%$, and $8.32 \%$ for MMTNFs with concentration of $0.2 \%, 0.4 \%$, $0.6 \%, 0.8 \%$, and $1 \%$.

The present study focused on the benefits of using MMTNFs in a PHE, while the effects of MMT weight fraction on the thermal performance have been experimentally investigated. The results showed that the thermal performance of PHE working with MMTNFs is superior to that of the water as a coolant working fluid. The change in the MMT concentration exhibited a dual behavior in the thermal performance. The highest performance was achieved in $0.6 \mathrm{wt} \%$ of MMT. This optimum concentration was respectively yielded 17.65 and $7.82 \%$ enhancement in the heat transfer rate and thermal efficiency. In the MMT nanofluids with lower concentration than $0.6 \mathrm{wt} \%$, the improving of heat transfer was accompanied by the low increment of pumping power. Whereas, the growth of pumping power was mutated at the concentration above $0.6 \%$.

The term of thermal nanofluid is a relatively new application of montmorillonite clay that requires detailed articulation of the montmorillonite dispersion and its colloidal properties. Especially, a realistic evaluation of the shape of suspended particles and a detailed study of their interaction requires advanced analyzes such as transmission electron microscopy (TEM). This is the main limitation of the present study, which can be considered as a future direction for research. To introduce new research topics in this field, the following recommendations are provided:

- The use of metal decorated montmorillonite as a high energy additive for thermal application.

- Investigating the effect of MMT nanofluid flow rate (Reynolds number) on the thermal performance of 
heat exchanger by evaluating convection heat transfer coefficient.

- Appling the MMT nanofluid in other thermal system with various heat transfer mechanisms such as forced convection, natural convection, boiling and condensation, and radiation.

\section{Compliance with ethical standards}

Conflict of interest The authors declare that they have no conflict of interest. The authors declare that the article has not received prior publication and is not under consideration for publication elsewhere.

\section{References}

1. Mahbubul IM, Chong TH, Khaleduzzaman SS, Shahrul IM, Saidur $\mathrm{R}$, Long BD, Amalina MA (2014) Effect of ultrasonication duration on colloidal structure and viscosity of alumina-water nanofluid. Ind Eng Chem Res 53(16):6677-6684

2. Mirzaei M, Rafsanjani HK (2017) An automatic algorithm for determination of the nanoparticles from TEM images using circular Hough transform. Micron. 96:86-95

3. Sarafraz MM, Nikkhah V, Madani SA, Jafarian M, Hormozi F (2005) Low-frequency vibration for fouling mitigation and intensification of thermal performance of a plate heat exchanger working with CuO/water nanofluid. Appl Thermal Eng 121:388-399

4. Mirzaei $M(2017)$ Experimental investigation of the assessment of $\mathrm{Al}_{2} \mathrm{O}_{3}-\mathrm{H}_{2} \mathrm{O}$ and $\mathrm{CuO}-\mathrm{H}_{2} \mathrm{O}$ nanofluids in a solar water heating system. J Energy Storage 14:71-81

5. Zhang W, Taleghani A, Ayani M, Hajizadeh MR, Babazadeh H (2020 Jun 4) Nanoparticle and shape factor for improving solidification rate. Int J Mod Phys C

6. Huminic G, Huminic A (2012) Application of nanofluids in heat exchangers: a review. Renew Sustain Energy Rev 16(8):5625-5638

7. Manh TD, Marashi M, Mofrad AM, Taleghani AH, Babazadeh H (2020 Apr 27) The influence of turbulator on heat transfer and exergy drop of nanofluid in heat exchangers. J Thermal Anal Calorim.

8. Pantzali MN, Kanaris AG, Antoniadis KD, Mouza AA, Paras SV (2009) Effect of nanofluids on the performance of a miniature plate heat exchanger with modulated surface. Int J Heat Fluid Flow 30(4):691-699

9. Haghshenas FM, Talaie MR, Nasr S (2011) Numerical and experimental investigation of heat transfer of $\mathrm{ZnO}$ /water nanofluid in the concentric tube and plate heat exchangers. Thermal Sci 15(1):183-194

10. Tiwari AK, Ghosh P, Sarkar J (2013) Performance comparison of the plate heat exchanger using different nanofluids. Exp Thermal Fluid Sci 49:141-151

11. Tiwari AK, Ghosh P, Sarkar J (2013) Heat transfer and pressure drop characteristics of $\mathrm{CeO}_{2}$ /water nanofluid in plate heat exchanger. Appl Therm Eng 57(1-2):24-32

12. Taghizadeh-Tabari Z, Heris SZ, Moradi M, Kahani M (2016) The study on application of $\mathrm{TiO} 2 /$ water nanofluid in plate heat exchanger of milk pasteurization industries. Renew Sustain Energy Rev 58:1318-1326
13. Maré $T$, Halelfadl $S$, Sow $O$, Estellé $P$, Duret $S$, Bazantay $F$ (2011) Comparison of the thermal performances of two nanofluids at low temperature in a plate heat exchanger. Exp Thermal Fluid Sci 35(8):1535-1543

14. Wang Z, Wu Z, Han F, Wadsö L, Sundén B (2018) Experimental comparative evaluation of a graphene nanofluid coolant in miniature plate heat exchanger. Int J Therm Sci 130:148-156

15. Duan H, Wang D, Li Y (2015) Green chemistry for nanoparticle synthesis. Chem Soc Rev 44(16):5778-5792

16. Aunkor MT, Mahbubul IM, Saidur R, Metselaar HS (2016) The green reduction of graphene oxide. RSC Adv 6(33):27807-27828

17. Liu N, Tang M (2020) Toxic effects and involved molecular pathways of nanoparticles on cells and subcellular organelles. J Appl Toxicol 40(1):16-36

18. Devendiran DK, Amirtham VA (2016) A review on preparation, characterization, properties and applications of nanofluids. Renew Sustain Energy Rev 60:21-40

19. Awua J, Ibrahim S, Kwaghger A (2017) Investigation of thermal conductivity of palm kernel fiber nanofluid using de-ionized water and ethylene glycol mixed at ratio of 50: 50 and 60: 40 . Magnesium 50:57-69

20. Ranjbarzadeh R, Moradikazerouni A, Bakhtiari R, Asadi A, Afrand M (2019) An experimental study on stability and thermal conductivity of water/silica nanofluid: eco-friendly production of nanoparticles. J Clean Prod 206:1089-1100

21. Essa FA, Elsheikh AH, Algazzar AA, Sathyamurthy R, Ali MK, Abd Elaziz M, Salman KH (2020) Eco-friendly coffee-based colloid for performance augmentation of solar stills. Process Saf Environ Prot 136:259-267

22. Moraes JD, Bertolino SR, Cuffini SL, Ducart DF, Bretzke PE, Leonardi GR (2017) Clay minerals: properties and applications to dermocosmetic products and perspectives of natural raw materials for therapeutic purposes-a review. Int J Pharm 534(1-2):213-219

23. Bergaya FB, Lagaly G. General introduction: clays, clay minerals, and clay science. In: Developments in clay science 2013 (vol 5, pp 1-19). Elsevier

24. Alberola JA, Mondragón R, Juliá JE, Hernández L, Cabedo L (2014) Characterization of halloysite-water nanofluid for heat transfer applications. Appl Clay Sci 99:54-61

25. Joussein E, Petit S, Churchman J, Theng B, Righi D, Delvaux B (2005) Halloysite clay minerals-a review. Clay Miner 40(4):383-426

26. Chakraborty S, Sarkar I, Haldar K, Pal SK, Chakraborty S (2015) Synthesis of $\mathrm{Cu}-\mathrm{Al}$ layered double hydroxide nanofluid and characterization of its thermal properties. Appl Clay Sci 107:98-108

27. Zimmer A, de Andrade MJ, Sánchez FA, Takimi AS. Use of natural and modified natural nanostructured materials. In: Nanostructured materials for engineering applications 2011, pp 157-172. Springer, Berlin

28. Gong Z, Liao L, Lv G, Wang X (2016) A simple method for physical purification of bentonite. Appl Clay Sci 119:294-300

29. Jayrajsinh S, Shankar G, Agrawal YK, Bakre L (2017) MontmorilIonite nanoclay as a multifaceted drug-delivery carrier: a review. J Drug Deliv Sci Technol 39:200-209

30. Bergaya F, Theng BKG, Lagaly G (2006) Handbook of clay science. Dev Clay Sci 1:1-1224

31. Schramm LL, Kwak JC (1982) Influence of exchangeable cation composition on the size and shape of montmorillonite particles in dilute suspension. Clays Clay Miner 30(1):40-48

32. Tournassat C, Bizi M, Braibant G, Crouzet C (2011) Influence of montmorillonite tactoid size on $\mathrm{Na}-\mathrm{Ca}$ cation exchange reactions. J Colloid Interface Sci 364(2):443-454

33. Lagaly G, Ziesmer S (2003) Colloid chemistry of clay minerals: the coagulation of montmorillonite suspensions. Adv Coll Interface Sci 100:105-128 
34. Missana T, Adell A (2000) On the applicability of DLVO theory to the prediction of clay colloids stability. J Colloid Interface Sci 230(1):150-156

35. Hayati-Ashtiani M (2012) Use of FTIR spectroscopy in the characterization of natural and treated nanostructured bentonites (montmorillonites). Part Sci Technol 30(6):553-564

36. Poli AL, Batista T, Schmitt CC, Gessner F, Neumann MG (2008) Effect of sonication on the particle size of montmorillonite clays. J Colloid Interface Sci 325(2):386-390

37. Chakraborty S (2020) Panigrahi PK. A review. Applied Thermal Engineering, Stability of nanofluid, p 115259

38. Mirzaei M, Mohiabadi MZ (2018) Neural network modelling for accurate prediction of thermal efficiency of a flat plate solar collector working with nanofluids. Int J Ambient Energy 2018:1-1

39. Mirzaei M (2019) Experimental investigation of $\mathrm{CuO}$ nanofluid in the thermal characteristics of a flat plate solar collector. Environ Prog Sustain Energy 38(1):260-267

40. Bohren CF, Huffman DR (2008) Absorption and scattering of light by small particles. Wiley, London

41. Karickhoff SW, Bailey GW (1973) Optical absorption spectra of clay minerals. Clays Clay Miner 21(1):59-70

42. Liu $L$ (2011) A model for the viscosity of dilute smectite gels. Phys Chem Earth Parts A/B/C 36(17-18):1792-1798

43. Abend S, Lagaly G (2000) Sol-gel transitions of sodium montmorillonite suspensions. Appl Clay Sci 16(3-4):201-227

44. Kim S, Tserengombo B, Choi SH, Noh J, Huh S, Choi B, Chung H, Kim J, Jeong $\mathrm{H}$ (2019) Experimental investigation of heat transfer coefficient with $\mathrm{Al}_{2} \mathrm{O}_{3}$ nanofluid in small diameter tubes. Appl Therm Eng 146:346-355

45. Selvakumar RD, Dhinakaran S (2016) A multi-level homogenization model for thermal conductivity of nanofluids based on particle size distribution (PSD) analysis. Powder Technol 301:310-317

46. Gu B, Hou B, Lu Z, Wang Z, Chen S (2013) Thermal conductivity of nanofluids containing high aspect ratio fillers. Int J Heat Mass Transf 64:108-114
47. Min F, Peng C, Liu L (2015) Investigation on hydration layers of fine clay mineral particles in different electrolyte aqueous solutions. Powder Technol 283:368-372

48. Hamilton RL, Crosser OK (1962) Thermal conductivity of heterogeneous two-component systems. Ind Eng Chem Fundam 1(3):187-191

49. Ghosh MM, Ghosh S, Pabi SK (2013) Effects of particle shape and fluid temperature on heat-transfer characteristics of nanofluids. J Mater Eng Perform 22(6):1525-1529

50. Hwang Y, Park HS, Lee JK, Jung WH (2006) Thermal conductivity and lubrication characteristics of nanofluids. Curr Appl Phys 6:e67-e71

51. Evans W, Prasher R, Fish J, Meakin P, Phelan P, Keblinski P (2008) Effect of aggregation and interfacial thermal resistance on thermal conductivity of nanocomposites and colloidal nanofluids. Int J Heat Mass Transf 51(5-6):1431-1438

52. Kumar V, Tiwari AK, Ghosh SK (2016) Effect of chevron angle on heat transfer performance in plate heat exchanger using $\mathrm{ZnO} /$ water nanofluid. Energy Convers Manag 118:142-154

53. Khoshvaght-Aliabadi M, Hormozi F, Zamzamian A (2014) Experimental analysis of thermal-hydraulic performance of copperwater nanofluid flow in different plate-fin channels. Exp Thermal Fluid Sci 52:248-258

54. Pandey SD, Nema VK (2012) Experimental analysis of heat transfer and friction factor of nanofluid as a coolant in a corrugated plate heat exchanger. Exp Thermal Fluid Sci 38:248-256

Publisher's Note Springer Nature remains neutral with regard to jurisdictional claims in published maps and institutional affiliations. 